\title{
Stability of the Antioxidant Activity of Flavonoids after Gamma Irradiation
}

\author{
Antônio Fernando de Melo Vaz ${ }^{1}$, Marthyna Pessoa de Souza ${ }^{1}$, Adriana Carla Cavalcante Malta \\ Argôlo ${ }^{1}$, Ana Maria Mendonça de Albuquerque Melo $^{2}$, Maria Luiza Vilela Oliva ${ }^{3}$, Haroldo Sátiro \\ Xavier $^{4}$, Luana Cassandra Breitenbach Barroso Coelho ${ }^{1}$, Maria Tereza dos Santos Correia ${ }^{{ }^{*}}$
}

\footnotetext{
${ }^{1}$ Department of Biochemistry, Federal University of Pernambuco, Recife, Brazil; ${ }^{2}$ Department of Biophysics and Radiobiology, Federal University of Pernambuco, Recife, Brazil; ${ }^{3}$ Department of Biochemistry, Federal University of São Paulo, São Paulo, Brazil; ${ }^{4}$ Department of Pharmaceutical Science, Federal University of Pernambuco, Recife, Brazil.

Email: *melo_vaz@ig.com.br
}

Received April 26 ${ }^{\text {th }}, 2011$; revised May 26 ${ }^{\text {th }}, 2011$; accepted June $4^{\text {th }}, 2011$.

\begin{abstract}
Food irradiation has the purpose of destroying insects or microorganisms, thereby increasing the safety and shelf life of foods. Flavonoids are ubiquitous plant secondary products with radical scavenger ability. In the present study their antioxidant stability after gamma irradiation was evaluated. The flavonoids showed fast scavenger ability measured with the 2.2-diphenyl-1-picrylhydrazyl radical (DPPH) after high doses of radiation. The low damage caused by irradiation on antioxidant capacity of the flavonoids shows their potential use in combating chemical oxidation of biomolecules in irradiated foods.
\end{abstract}

Keywords: Flavonoid, Food Irradiation, Scavenger Capacity, Gamma Irradiation

\section{Introduction}

Radiation treatments of biological materials have been applied for various processes: sterilization of materials, reduction of microbial contamination of food, and increasing the safety and shelf life of foods. Gamma irradiation can damage biomolecules directly by rupturing covalent bonds as a result of transfer of photon energy, and indirectly, by producing free radicals and other non-radical reactive oxygen species [1]. Investigations have shown that free radicals cause chemical oxidation [2] and oxidative stress [3] which makes the recovery of biologically active materials unlikely.

Flavonoids are among the most ubiquitous of plant secondary metabolites and aid in the reproduction and protecttion of plants [4]. Their low toxicity and high antioxidant activity [5] have been documented. The evaluation of the radioprotective effects of flavonoids on organoleptic properties, sensory and cytological has been described in strawberries [6]. Recently, some studies showed the radioprotective effects of flavonoids in gamma-irradiated mice [7-9]. Irradiated flavonoid solutions produce chemical reactions between the solute and reactive species, which are the result of the radiolyzed solvent operating to quickly repair the chemical modifications to biomolecules $[10,11]$.
One of the most important probes for evaluating the fast repair of antioxidant capacity is the 2.2-diphenyl-1picrylhydrazyl radical (DPPH), a stable nitrogen synthetic radical [12]. Therefore, the aim of our study was to evaluate the free radical scavenging ability and radiostability of flavonoids isolated from $S$. jacobinensis bark after a high dose of $\gamma$-radiation.

\section{Materials and Methods}

\subsection{Flavonoid Isolation}

S. jacobinensis bark was collected from trees in the semi-arid region of the state of Pernambuco, Brazil. S. jacobinensis dry bark was mixed in a beaker with $250 \mathrm{ml}$ of ethanol/acetic acid/water (70:4:26, v:v:v) for $2 \mathrm{~h}$ at $4^{\circ} \mathrm{C}$. The extract containing flavonoids was chromatographed in an anion-exchange DEAE-Cellulose (Sigma) column $(40 \times 2.5 \mathrm{~cm})$ equilibrated with ethanol-water $(70: 30, v: v)$. Elution was performed with ethanol-acetic acid-water (70:4:26, v:v:v) at a flow rate of $2 \mathrm{ml} / \mathrm{min}$. Each fraction collected was checked by thin layer chromatography (TLC) to determine their compositions using ethyl acetate/formic acid/acetic acid/water (100:11:11:26, $\mathrm{v}: \mathrm{v}: \mathrm{v}: \mathrm{v})$. Vanillin dipping in hydrochloric acid was used for detection under UV (254 nm). TLC conditions were 
optimized using $(+)$-catechin standard. The obtained flavonoid was denominated SejaBF.

\subsection{LC-ESI-MS}

The analysis of SejaBF was revealed by LC analyses (Waters) with a diode-array detector, in a Deltapak $\mathrm{C}_{18}$ column $(2.0 \mathrm{~mm} \times 150 \mathrm{~mm} ; 3.5 \mu \mathrm{m}$ size; $60 \AA$; Walters $)$ at a flow rate of $0.4 \mathrm{ml} / \mathrm{min}$, keeping the column at a constant temperature $\left(30^{\circ} \mathrm{C}\right.$ ) and using $0.1 \% \mathrm{TFA} / \mathrm{H}_{2} \mathrm{O}$ (solvent $\mathrm{A}$ ) and $90 \% \mathrm{ACN} / 0.1 \% \mathrm{TFA} / \mathrm{H}_{2} \mathrm{O}$ (solvent B) as solvents. A linear gradient elution was used with $5 \%-95 \% \mathrm{~B}$ in $\mathrm{A}$ for $30 \mathrm{~min}$. The molecular mass was determined by electrospray ionization ion-trap mass spectrometry using a Waters LC/ESI+/MS scanning at $200-2500 \mathrm{~m} / \mathrm{z}$.

\subsection{Gamma Irradiation}

The SejaBF aliquots $(1 \mathrm{mg} / \mathrm{ml})$ in $10 \mathrm{mM}$ phosphate buffer $(\mathrm{pH} 7.0)$ in borosilicate glass vials $(16-125 \mathrm{~mm})$ were frozen and irradiated in atmospheric $\mathrm{O}_{2}$ using a Gammacell 220 Excel ${ }^{60} \mathrm{Co}$ gamma ray irradiator (Ontario, Canada) at doses of $0.020,0.8,3.0$ and $35 \mathrm{kGy}$ at a rate of $8.8 \mathrm{kGy} / \mathrm{h}$.

\subsection{Antioxidant Activity Determination}

Spectrophotometric analysis was used to determine the inhibition concentration $\left(\mathrm{IC}_{50}\right)$ and the inhibition percentage (IP). $\mathrm{IC}_{50}$ is the amount of antioxidant necessary to decrease the initial concentration of DPPH radical $(75$ $\mu \mathrm{M})$ by $50 \%$. IP is the percentage of total DPPH radical $(75 \mu \mathrm{M})$ which reacted with antioxidant at the steady state $(20 \mathrm{~min})$. The experiments were performed using the SmartSpec 3000 spectrophotometer (Bio-Rad) according to the methods of Soler-Rivas [13] and Moure [14]. Pure methanol was used as a negative control. $(+)$-Catechin and ascorbate in methanol $(1 \mathrm{mg} / \mathrm{ml})$ were used as positive controls. The disappearrance of the DPPH radical was monitored by the decrease in absorbance at $515 \mathrm{~nm}$. The DPPH radical concentration in the reaction mixture was calculated by the calibration curve according to the following nonlinear regression equation $(R=0.997): \mathrm{A}_{515 \mathrm{~nm}}=0.01029[\mathrm{DPPH}]-0.0177$, where [DPPH] is expressed in $\mathrm{mg} / \mathrm{ml}$.

\subsection{Statistical Analysis}

Data are presented as mean \pm S.E.M of five independent experiments. The curve, student's t test and its 95\% confidence intervals (CI 95\%) were obtained by nonlinear regression using the GraphPrism ${ }^{\circledR}$ program (GraphPad Software Inc., San Diego, CA, USA).

\section{Results and Discussion}

Flavonoids, denominated $S$. jacobinensis bark flavonoids (SejaBF), were isolated and partially characterized by a combination of anion-exchange DEAE-Cellulose and high performance liquid chromatography. The LC/MS protocol showed positive molecular ion m/z 307 (M+ 1) -epigallocatechin and $\mathrm{m} / \mathrm{z} 613(2 \mathrm{M}+1)$, which could be an adduct of epigallocatechin (Figure 1). Adduct formation with sodium and a protonated water adduct have been observed in positive ion mode for most compounds

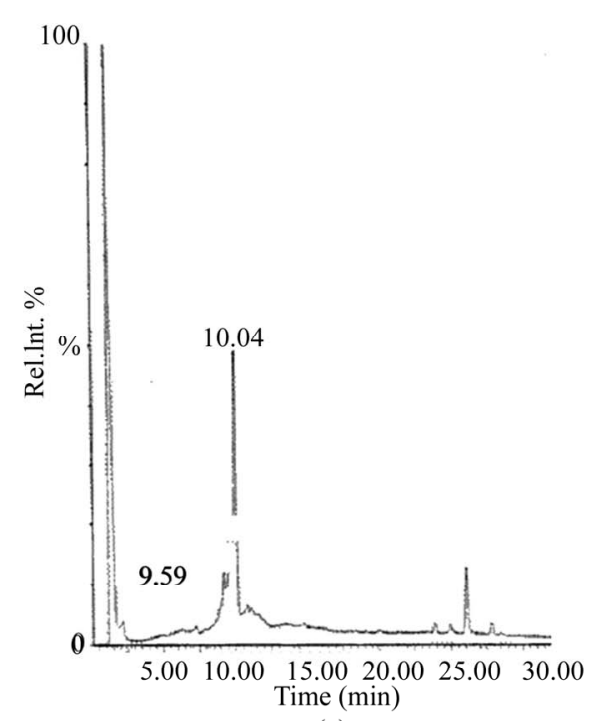

(a)

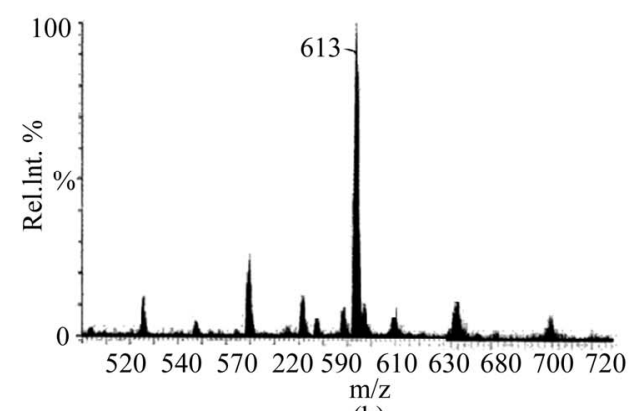

(b)

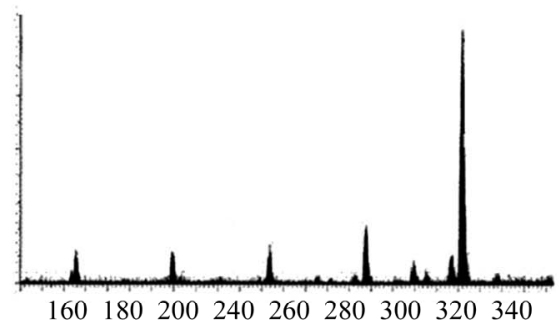

(c)

Figure 1. S. jacobinensis flavonoids (SejaBF) ESI-MS spectra. SejaBF reverse phase chromatography in $\mathrm{C}_{18}$ column by HPLC system (a). MS with retention time of $10.04 \mathrm{~min}(\mathrm{~b})$ and $9.59 \mathrm{~min}$ (c). 
[15]. The identification of heterogeneous adducts by antioxidant capacity and HPLC/MS protocol was demonstrated in order to perform an analysis of the procyanidins [16]. However, UV/VIS spectrum and a fragmentation pattern (MS/MS) should be used in future studies for complete characterization.

SejaBF exhibited high antioxidant capacity by the DPPH method when compared to ascorbate, an antioxidant widely used as a standard. However, its antioxidant activity decreased after irradiation, in relation to the $\mathrm{IC}_{50}$ and IP (Table 1). IP reduction (19.2\% at high dose) was significant although the $\mathrm{IC}_{50}$ reduction was not.

DPPH radical scavenger capacity $\left(\% \mathrm{DPPH}_{\mathrm{REM}}\right)$ was significantly reduced only in the initial $5 \mathrm{~min}$ after a high dose of radiation (Figure 2). The DPPH radical is scavenged by antioxidants through donation of hydrogen to form a stable, reduced DPPH molecule. The radical scavenger is reduced after high doses of gamma radiation due to displacement from the B-ring to the 2.3-double bond, indicating a relatively small reactivity (because of the absence of high density spin on a given site) for these intermediate species $[17,18]$. The existence of such intermediate species after irradiation apparently does not abolish the antioxidant properties and can maintain the radioprotective effects of flavonoids. A feature already observed in gamma-irradiated strawberry [6]. Our results are in good agreement with the presence of stabilized quinones, which have been observed after $\mathrm{H}$-abstraction from the B-ring of flavonoids in radiolytic solutions [19]. Irradiation can cause oxidative damage and impair flavor in food. However, the action of effective and radiostable natural antioxidants may prevent chemical oxidation of biomolecules in irradiated food.

\section{Acknowledgements}

This research was financially supported by the Brazilian Council for Scientific and Technological Development $(\mathrm{CNPq})$ for research grants and Ministry of Science and Technologies of Brazil, Higher Education Improvement of Coordination (CAPES). We are grateful to the Department of Nuclear Energy of the Federal University of

Table 1. Radical scavenging performance.

\begin{tabular}{lcc}
\hline \multicolumn{1}{c}{ Samples } & IP $(\%)$ & IC $_{\mathbf{5 0}}(\mathbf{m g} / \mathbf{g} \mathbf{D P P H})$ \\
\hline SejaBF 20 Gy & $89.13^{\mathrm{a}}$ & $8.11 \pm 0.14^{\mathrm{a}}$ \\
SejaBF 800 Gy & $7.90 \pm 0.14^{\mathrm{a}}$ & $88.30^{\mathrm{a}}$ \\
SejaBF 3 kGy & $79.63^{\mathrm{b} \#}$ & $12.70 \pm 0.14^{\mathrm{b} \#}$ \\
SejaBF 35 kGy & $70.88^{\mathrm{c} \#}$ & $21.17 \pm 0.28^{\mathrm{c \#}}$ \\
SejaBF non-irradiated & $90.11^{\mathrm{a}}$ & $8.89 \pm 0.28^{\mathrm{a}}$ \\
(+)-catechin & $90.85^{\mathrm{a}}$ & $14.53 \pm 0.01^{\mathrm{d}}$ \\
Ascorbate & $39.22^{\mathrm{b}}$ & $92.94 \pm 0.01^{\mathrm{e}}$ \\
\hline
\end{tabular}

Values with the same superscript letter are not significantly different at $p<$ 0.05 (Student's T-test). IC I $_{50}$ and IP $(0.5 \mathrm{mg} / \mathrm{ml})$ of SejaBF were calculated at the steady state (20 min). ${ }^{\#}$ Values of IP (\%) are significantly different at $p<$ 0.05 in relation to non-irradiated SejaBF.

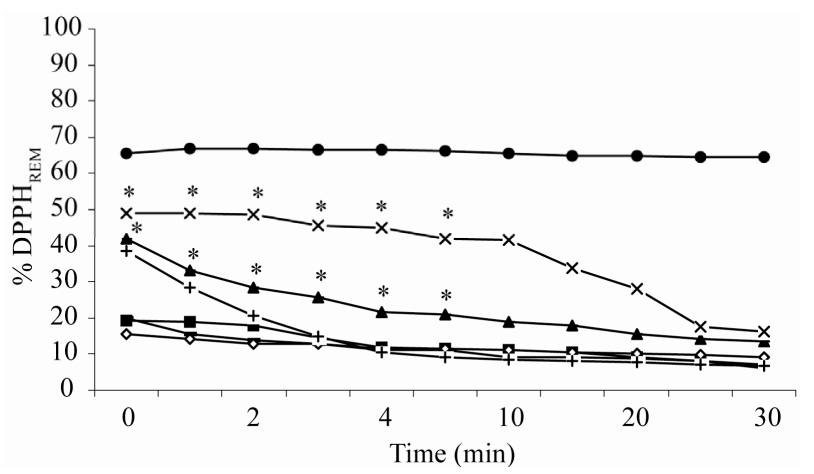

Figure 2. Kinetic behaviour of irradiated antioxidants. The error in the determination of \%DPPH ${ }_{\mathrm{REM}}$ to relative values of different doses is approximately $\pm 1 \%$, smaller than the size of the symbols. *Values significantly different at $p<$ 0.05 (Student's T-test) in relation to $(\circ)$ non-irradiated $S$. jacobinensis flavonoids (SejaBF). SejaBF after irradiation:

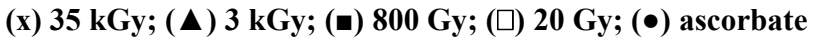
and $(+)$-catechin.

Pernambuco (UFPE) for access to their facility and for assistance.

\section{REFERENCES}

[1] E. S. Kempner, "Effects of High-Energy Electrons and Gamma Rays Directly on Protein Molecules," Journal of Pharmaceutical Sciences, Vol. 90, No. 10, 2001, pp. 1637-1646. doi:10.1002/jps.1114

[2] J. Terao, M. Piskulaand and Q. Yao, "Protective Effect of Epicatechin, Epicatechin Gallate and Quercetin on Lipid Peroxidation in Phospholipid Bilayers," Archives of Biochemistry and Biophysics, Vol. 308, No. 1, 1994, pp. 278-284. doi:10.1006/abbi.1994.1039

[3] O. I. Aruoma, "Free Radicals, Oxidative Stress, and Antioxidants in Human Health and Disease," Journal of the American Oil Chemists Society, Vol. 75, No. 2, 1998, pp. 199-212. doi:10.1007/s11746-998-0032-9

[4] B. Winkel-Shirley, "Biosynthesis of Flavonoids and Effects of Stress," Current Opinion in Plant Biology, Vol. 5, No. 3, 2002, pp. 218-223. doi:10.1016/S1369-5266(02)00256-X

[5] M. Garcia-Alonso, G. Rimbach, M. Sasai, M. Nakahara, S. Matsugo, Y. Uchida, J. C. Rivas-Gonzalo and S. de Pascual-Teresa, "Electron Spin Resonance Spectroscopy Studies on the Free Radical Scavenging Activity of Wine Anthocyanins and Pyranoanthocyanins," Molecular Nutrition \& Food Research, Vol. 49, No. 12, 2005, pp. 1112- 1119. doi: $10.1002 / \mathrm{mnfr} .200500100$

[6] F. Breitfellner, S. Solar and G. Sontag, "Effect of Gamma Irradiation on Flavonoids in Strawberries," European Food Research \& Technology, Vol. 215, No. 1, 2002, pp. 28-31. doi:10.1007/s00217-002-0536-8

[7] N. Orsolić, V. Benković, A. Horvat-Knezević, N. Kopjar, I. Kosalec, M. Bakmaz, Z. Mihaljević, K. Bendelja and I. Basić, "Assessment by Survival Analysis of the Radio- 
protective Properties of Propolis and its Polyphenolic Compounds," Biological \& Pharmaceutical Bulletin, Vol. 30, No. 5, 2007, pp. 946-951. doi:10.1248/bpb.30.946

[8] V. Benković, N. Orsolić, A. H. Knezević, S. Ramić, D. Dikić, I. Basić and N. Kopjar, "Evaluation of the Radioprotective Effects of Propolis and Flavonoids in GammaIrradiated Mice: The Alkaline Comet Assay Study," Biological \& Pharmaceutical Bulletin, Vol. 31, No. 1, 2008, pp. 167-172. doi:10.1248/bpb.31.167

[9] V. Benković, A. H. Knezević, D. Dikić, D. Lisicić, N. Orsolić, I. Basić and N. Kopjar, "Radioprotective Effects of Quercetin and Ethanolic Extract of Propolis in Gamma-Irradiated Mice," Archives of Industrial Hygiene \& Toxicology, Vol. 60, No. 2, 2009, pp. 129-138. doi:10.2478/10004-1254-60-2009-1908

[10] Y. Hanasaki, S. Ogawa and S. Fukui, "The Correlation between Active Oxygens Scavenging and Antioxidative Effects of Flavonoids," Free Radical Biology \& Medicine, Vol. 16, No. 6, 1994, pp. 845-850. doi:10.1016/0891-5849(94)90202-X

[11] D. Kozlowski, P. Marsal, M. Steel, R. Mokrini, J. L. Duroux, R. Lazzaroni and P. Trouillasa, "Theoretical Investigation of the Formation of a New Series of Antioxidant Depsides from the Radiolysis of Flavonoid Compounds," Radiation Research, Vol. 168, No. 2, 2007, pp. 243-252. doi:10.1667/RR0824.1

[12] W. Brand-Williams, M. E. Cuvelier and C. Berset, "Use of a Free Radical Method to Evaluate Antioxidant Activity," LWT-Food Science and Technology, Vol. 28, No. 1, 1995, pp. 25-30.

[13] C. Soler-Rivas, J. C. Espın and H. J. Wichers, “An Easy and Fast Test to Compare Total Free Radical Scavenger Capacity of Foodstuffs," Phytochemistry Analysis, Vol.
11 , No. 5, 2000, pp. $1-9$. doi:10.1002/1099-1565(200009/10)11:5<330::AID-PCA5 $34>3.0 . \mathrm{CO} ; 2-\mathrm{G}$

[14] A. Moure, D. Franco, J. Sineiro, H. Dominguez, M. J. Núñes and J. M. Lema, "Antioxidant Activity of Extracts from Gevuina Avellana and Rosa Rubiginosa Defatted Seeds," Food Research International, Vol. 34, No. 2-3, 2001, pp. 103-109. doi:10.1016/S0963-9969(00)00136-8

[15] P. Swatsitang, G. Tucker, K. Robards and D. Jardine, "Isolation and Identification of Phenolic Compounds in Citrus Sinensis," Analytica Chimica Acta, Vol. 417, No. 2, 2000, pp. 231-240. doi:10.1016/S0003-2670(00)00937-5

[16] D. Ferreira and D. Slade, "Oligomeric Proanthocyanidins: Naturally Occurring O-Heterocycles," Natural Product Reports, Vol. 19, No. 5, 2002, pp. 517-541. doi:10.1039/b008741f

[17] C. Zhao, Y. Shi, W. Wang, W. Lin, B. Fan, Z. Jia, S. Yao and R. Zheng, "Fast Repair Activities of Quercetin and Rutin toward dGMP Hydroxyl Radical Adducts," Radiation Physics and Chemistry, Vol. 63, No. 2, 2002, pp. 137-142. doi:10.1016/S0969-806X(01)00224-9

[18] A. Marfak, P. Trouillas, D. P. Allais, Y. Champavier, C. A. Calliste and J. L. Duroux, "Radiolysis of Kaempferol in Water/Methanol Mixtures. Evaluation of Antioxidant Activity of Kaempferol and Products Formed," Journal of Agricultural and Food Chemistry, Vol. 51, No. 5, 2003, pp. 1270-1277. doi:10.1021/jf020836g

[19] A. S. Pannala, T. S. Chan, P. J. O'Brien and C. A. RiceEvans, "Flavonoid B-Ring Chemistry and Antioxidant Activity: Fast Reaction Kinetics," Biochemical and Biophysical Research Communications, Vol. 282, No. 5, 2001, pp. 1161-1168. doi:10.1006/bbrc.2001.4705 